ICAASET-2021, 20-21 May, 2021, K.R. Mangalam University, Gurugram

International Journal of Technical Research \& Science (Special Issue) ISSN No.:2454-2024 (online)

\title{
POWER SYSTEM STUDIES TO IDENTIFY LOSSES AND EXISTING DIFFERENCES
}

\author{
Bhavesh Vyas ${ }^{1}$, Mahaveer Prasad Sharma², Mukesh Kumar Gupta ${ }^{3}$, M. K. Banerjee \\ E-Mail Id: bhavesh.vyas@krmangalam.edu.in, mahavir_sh@rediffmail.com, \\ mukeshkr.gupta@mygyanvihar.com,mkbanerjee@hotmail.com \\ ${ }^{1}$ K R Mangalam University, Gurugram, India \\ ${ }^{2}$ Rajasthan Vidhut Prasaran Nigam, Jaipur, India \\ ${ }^{3}$ Suresh Gyanvihar University, Jaipur, India \\ ${ }^{4}$ Suresh Gyanvihar University, Jaipur, India
}

\begin{abstract}
Research paper presents simulation study of submitting technical losses of existing and renewable integrated real time network. All along with variations recorded in voltage profile at $400 \mathrm{KV}$ levels are deliberately presented with test network modeling of existing system that is a part of Indian National grid synchronized at $765 \mathrm{KV}$ and $400 \mathrm{KV}$ voltage levels. Disturbances recorded for the financial year 2018-19 is being practiced to judge the increment of losses that are possibly to raise with the adherence of renewable energy system from $20 \%$ to $70 \%$ in a gap of ten percent. The paper discusses test network modeling basics, operations strategy in case of voltage issues are briefed. System deficiencies are represented with possible suggestions.
\end{abstract}

\section{INTRODUCTION}

Power System Network is the sum total of power generation, transmission and distribution to the infinitely connected load end termed as consumer. As the distance from generator increases the losses and differences in network keeps on multiplying. The present form of grid network is very much improved and advanced as compared to earlier versions. Bidirectional power flows, demand side management, utilization of smart meters have raised the role of consumers too in advancing the grid. System at present is working in its restructured stage, definitely the upcoming time will may provide wide changes in terms of source wise composition of power is concerned. Although obtaining huge power from coal at present, the level of power generation from renewable energy sources is continuously changing its digits from double to triple. As a result, it may change the old parameters soon. Concerning towards environment issues and pandemic situation have alarmed power system engineers to utilize and perform the grid operations in sustainable ways. Government of India are continuously modifying old rules and regulations to channelize the grid structure as per upcoming modifications and requirements.

Work carried in this paper is to identify the basic problems of network in operations with grid over huge area such as Rajasthan State Power System Network is utilized hereby for study. The respective test network could be termed as modern power system since it consists of demand side management as grid feature tool even all the arrangement are made on day ahead basis with proper planning from generation ends. Along with this state load dispatch centers took the responsibility of major operations and decisions if in case to be taken upon to maintain grid levels and limits when required upon. As per there instruction operator carries out exercises in the field.

Since from the last few years ratio of upcoming solar and wind integration to grid is changing. Government plans to raise renewable energy sources have led to the increase of renewable energy content for the present and upcoming time. Large sized solar plants are going to cover up the desert areas of Rajasthan State to collect and provide maximum solar penetration as much as they can drew from the barren lands spread over thousands of kilometers. Government has started Green energy corridor schemes to evacuate large amount of renewable energy over $765 \mathrm{KV}$ corridors from the renewable rich states of India. So, raising the contribution of green energy that is reducing carbon foot prints over the areas as well as reducing the pollution issues attached with convention systems.

Many a times problem arises in grid network when conventional plants have to be managed with the intermittency issues related to renewable energy such as solar and wind because as solar starts from early morning 6 AM, rises peak at 11 to 12:00 PM in afternoon and last available till $6: 00 \mathrm{PM}$ of evening and vice versa with Wind. So, intermittency is there contributing a large amount of system is reduced suddenly cause huge unbalancing of power flows. Since it is daily based issue so obviously utilities have already prepared some steps or we can say some arrangements such as opening of lightly loaded circuits, Switching off Shunt capacitors from night till morning and so on. But still these arrangements are not enough or up to the mark as such issues of voltage profile, burnouts of equipment's, line outages at 400 and $220 \mathrm{KV}$ voltage level, abrupt tripping's etc. all such issues have been recorded regularly in past financial year. Thus, analysis over Rajasthan State power system is practiced with simulation studies. Basic idea of network along with modeling in software and issues recorded over past financial year 2018-19 will be discussed in the upcoming section. Targeted objectives of suggesting possible suggestions to the problems identified from the analytics of database will be also briefed.

\section{PROBLEM IDENTIFICATION}

Lacking in technology upgradation and non-availability of any schemes or methodology could be the major cause of unplanned work exercises. That may lead to over or under compensation of network at unnecessary areas in the network. As we see Rajasthan Power System has conventional thermal power plants in majority stack. 
ICAASET-2021, 20-21 May, 2020, K.R. Mangalam University, Gurugram

International Journal of Technical Research \& Science (Special Issue) ISSN No.:2454-2024 (online)
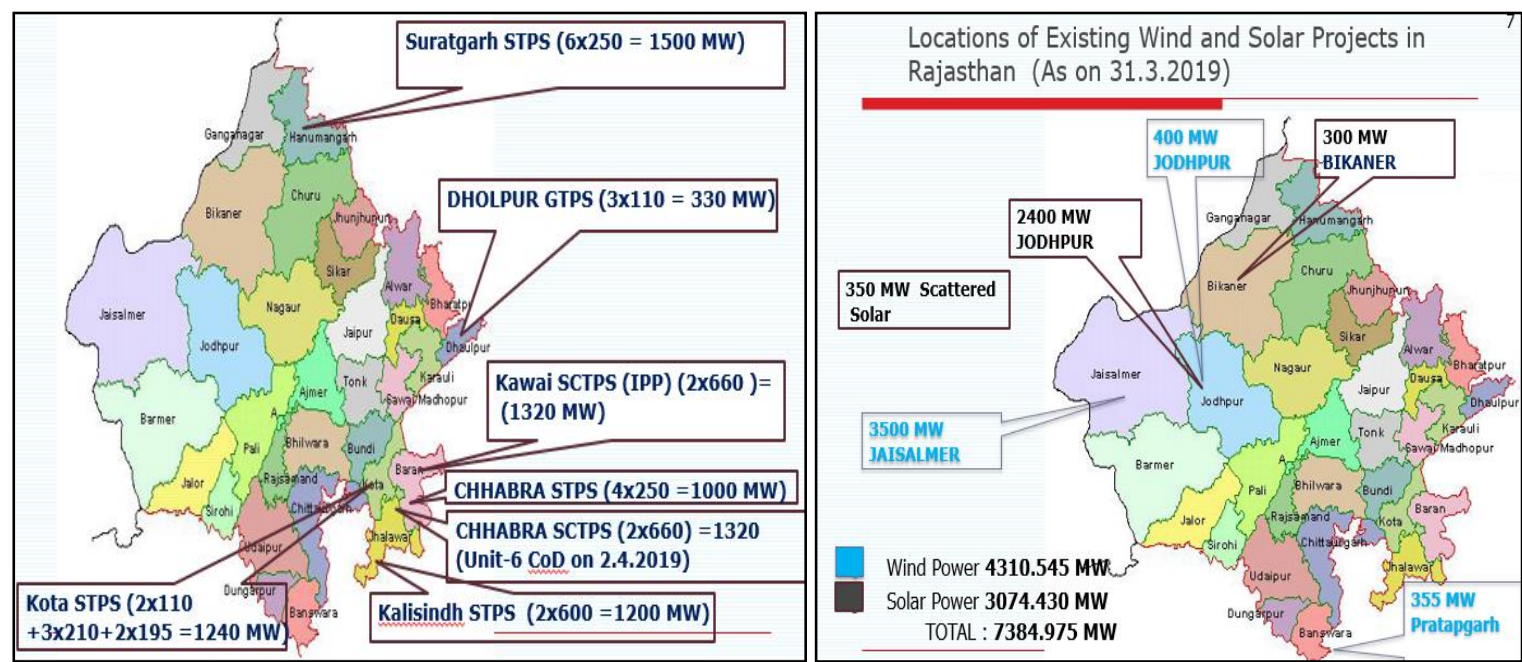

Fig. 2.1 Existing Coventional Plants and Renewable Generation of State Network

Also practicses performed since last ten years in raising the role of renewable energy in terms of solar and wind generation as shown in fig. 2.1. providing information about existing projects in renewable till 31:03:2019. Year wise progress in solar and wind generations is briefed in Plots of fig. 2.2 and 2.3 respectively.

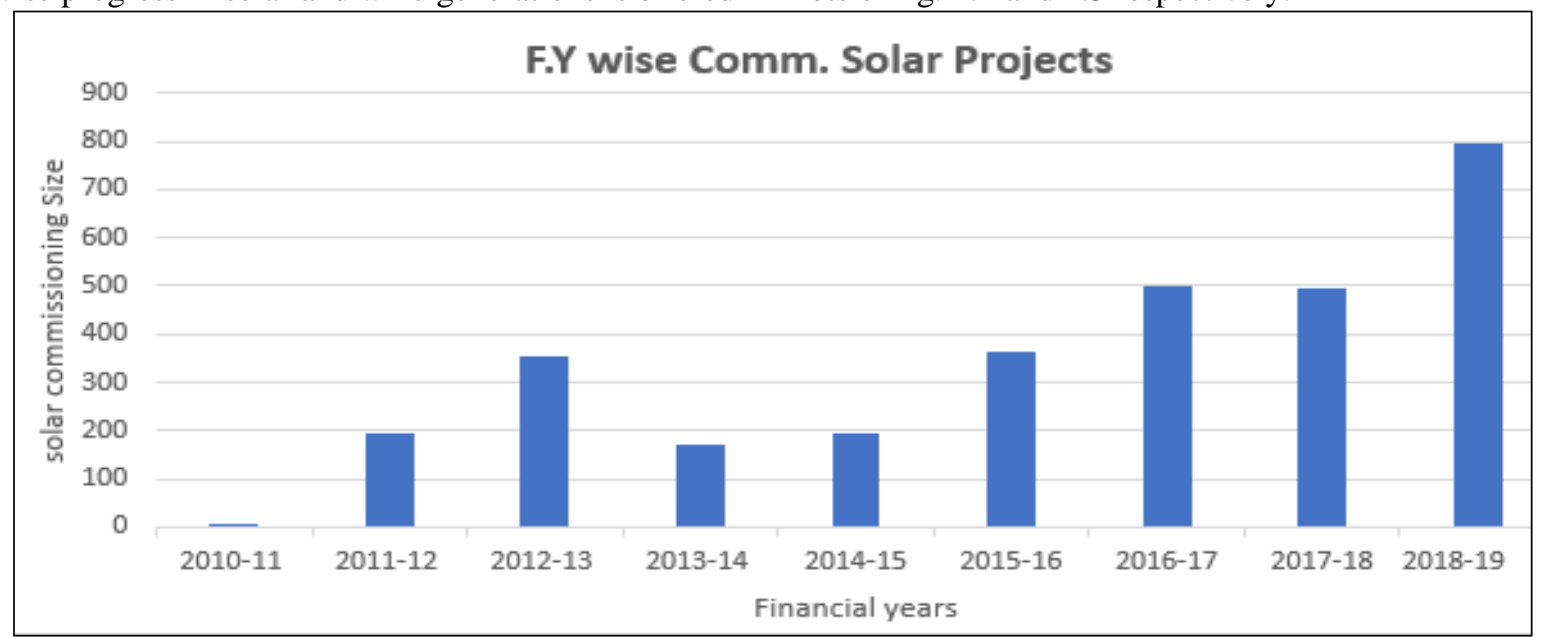

Fig. 2.2 Solar Projects Year wise Commisioning

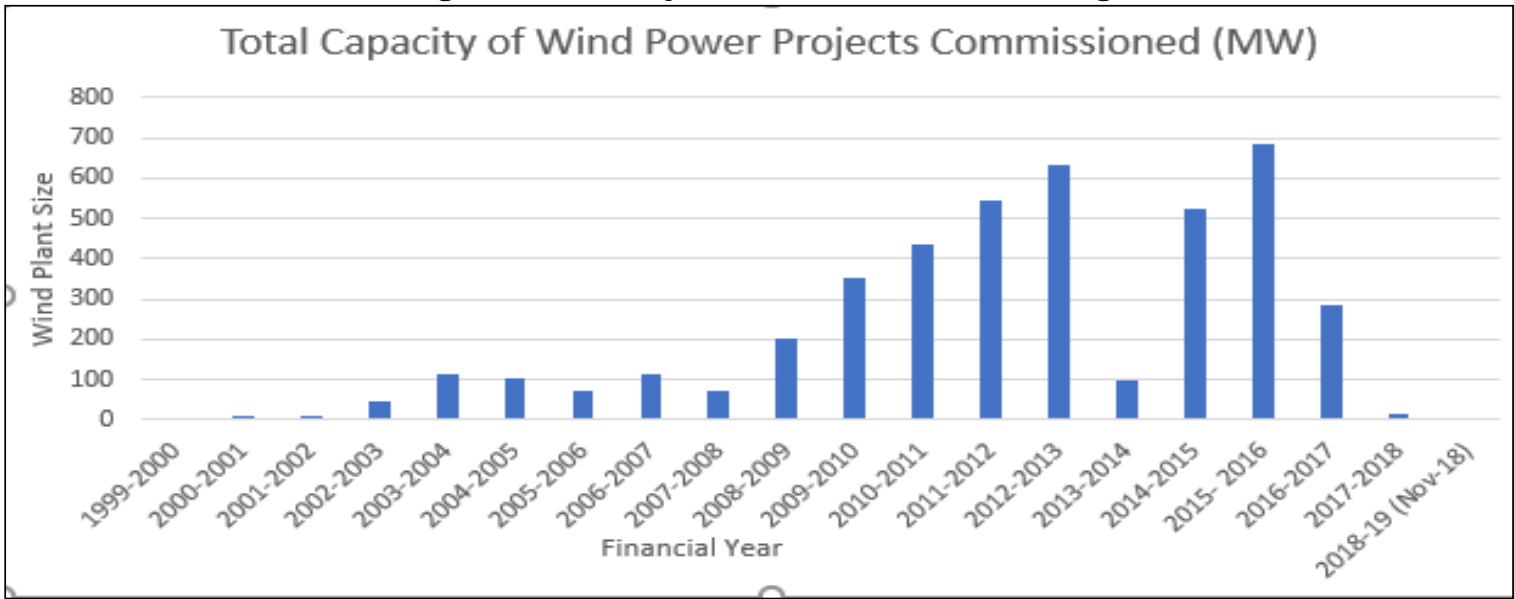

Fig. 2.3 Wind Projects Year wise Commisioning

Year 2018-19 shows progressive rise in solar addition during these years. Wind projects commissioning during year 2015-16 and 2012-13 is on higher scale, but afterwards it is down. Now following the available literature various technical issues prevailing in the power system are raised such as:

$>$ Practically implementing techniques/methods available at DISCOMS to maintain the Voltage variations happening at transmission level is missing.

$>$ No provisions are there at grid level to record the voltage variations and to keep deep study on them. Renewable integration misses the functionality of Ramp in/Out feature of conventional power plants thus resulting in low plant factors.

$>$ No contingency plan action is there to handle dynamic behaviors of grid in case when solar or wind stops supplying their supply in grid.

All the above queries are on the base of research operations carried in past. Handling the grid from SCADA view or from a dispatch center or generating center is totally different from literature material angle. Recorded database of peak voltages at $400 \mathrm{KV}$ GSS is provided in Table 2.1. 
ICAASET-2021, 20-21 May, 2020, K.R. Mangalam University, Gurugram

International Journal of Technical Research \& Science (Special Issue) ISSN No.:2454-2024 (online)

Table-2.1 Recorded Peak Voltages Of 400 KV GSS

\begin{tabular}{|c|c|c|c|c|c|}
\hline \multicolumn{6}{|c|}{ MONTH WISE RECORDED MAXIMUM 400 KV BUS VOLTAGE AT 400 KV GSS } \\
\hline Month & $\begin{array}{l}\text { BIKANER } \\
\text { GSS }\end{array}$ & $\begin{array}{l}\text { BARMER } \\
\text { GSS }\end{array}$ & ANTA GSS & $\begin{array}{l}\text { HINDAUN } \\
\text { GSS }\end{array}$ & $\begin{array}{l}\text { HIRAPURA } \\
\text { GSS }\end{array}$ \\
\hline Apr-18 & 429 & 429 & 419 & 430 & 425 \\
\hline May-18 & 425 & 422 & 419 & 435 & 425 \\
\hline Jun-18 & 429 & 427 & 416 & 437 & 424 \\
\hline Jul-18 & 425 & 428 & 417 & 429 & 425 \\
\hline Aug-18 & 425 & 426 & 417 & 425 & 423 \\
\hline Sep-18 & 425 & 427 & 415 & 427 & 425 \\
\hline Oct-18 & 422 & 420 & 414 & 425 & 423 \\
\hline Nov-18 & 425 & 417 & 417 & 428 & 424 \\
\hline Dec-18 & 425 & 420 & 416 & 430 & 424 \\
\hline Jan-19 & 425 & 425 & 416 & 435 & 426 \\
\hline Feb-19 & 425 & 428 & 414 & 429 & 427 \\
\hline Month & $\begin{array}{l}\text { PHAGI } \\
\text { GSS }\end{array}$ & $\begin{array}{l}\text { AJMER } \\
\text { GSS }\end{array}$ & BABAI GSS & $\begin{array}{l}\text { BHILWARA } \\
\text { GSS } \\
\end{array}$ & $\begin{array}{r}\text { MERTA } \\
\text { CITY GSS }\end{array}$ \\
\hline Apr-18 & 424 & 428 & 436 & 420 & 426 \\
\hline May-18 & 423 & 425 & 434 & 421 & 428 \\
\hline Jun-18 & 424 & 425 & 433 & 420 & 427 \\
\hline Jul-18 & 423 & 425 & 428 & 422 & 426 \\
\hline Aug-18 & 426 & 425 & 425 & 419 & 424 \\
\hline Sep-18 & 426 & 425 & 428 & 421 & 426 \\
\hline Oct-18 & 423 & 423 & 430 & 417 & 425 \\
\hline Nov-18 & 425 & 425 & 431 & 419 & 423 \\
\hline Dec-18 & 426 & 426 & 432 & 421 & 425 \\
\hline Jan-19 & 425 & 425 & 433 & 420 & 424 \\
\hline Feb-19 & 425 & 425 & 430 & 421 & 424 \\
\hline
\end{tabular}

As per voltage limit of operation is concerned various National/International obligations have already defined a fix limit under which operations should be there. But practical recordings violate the defined ones as provided in Table 2.2.

Table-2.2 Max/Min. Voltage Limit As Per IEGC/CEA

\begin{tabular}{|c|c|c|c|}
\hline S. No. & $\begin{array}{c}\text { Nominal System Voltage } \\
\text { (KV rms) }\end{array}$ & $\begin{array}{c}\text { Maximum } \\
\text { (KV rms) }\end{array}$ & $\begin{array}{c}\text { Minimum } \\
\text { (KV rms) }\end{array}$ \\
\hline 1 & 765 & 800 & 728 \\
\hline 2 & 400 & 420 & 380 \\
\hline 3 & 220 & 245 & 198 \\
\hline 4 & 132 & 145 & 122 \\
\hline 5 & 110 & 121 & 99 \\
\hline 6 & 66 & 72 & 60 \\
\hline 7 & 33 & 36 & 30 \\
\hline
\end{tabular}

Huge differences in peak values could be easily observed in the graph. It should be reduced otherwise it indirectly effects the equipment's of network. The upcoming section will detail the basic outlining of test network along with creation of simulation model in mipower software is briefed.

\section{MODELING DESCRIPTION OF TEST NETWORK}

Rajasthan State is connected with Northern Power Division and connected synchronously at all available higher voltage levels. Test network is the biggest part of India size wise with huge population as consumer more than 8 Crores. Source based data suggests that $57 \%$ is upcoming from coal based thermal plants. More than 600 Plus grid substation network is currently involved in transmission and distribution of electricity to consumer. Table 2.3. states that test system is having more than 0.39588 lakh circuit KM area covered till date 31st of March 2019, database locked till this date.

Table-2.3 Rajasthan State Power System Detailing

\begin{tabular}{|c|c|}
\hline Particulars GSS & No. of GSS/MVA Capacity till 31-03-2019 \\
\hline $765 \mathrm{kV}$ & 4 \\
\hline $400 \mathrm{kV}$ & 27 \\
\hline $220 \mathrm{kV}$ & 122 \\
\hline $132 \mathrm{kV}$ & 453 \\
\hline Total & $\mathbf{6 0 6}$ \\
\hline
\end{tabular}

DOI Number: https://doi.org/10.30780/specialissue-ICAASET021/007 
ICAASET-2021, 20-21 May, 2020, K.R. Mangalam University, Gurugram

International Journal of Technical Research \& Science (Special Issue) ISSN No.:2454-2024 (online)

As per the details briefed hereby the generation facility-based data is also shared in the upcoming Table where renewable and non-renewable sources both are classified as per there availability to the user. Large Sized network requires planning and operations at each level to work upon. State grid is maintained by grid operators as per the instruction received from the SLDC. Power map of Rajasthan power system provided hereby briefs the basic connectivity of complete network along with border tie line connections too provided in Fig. 2.4.

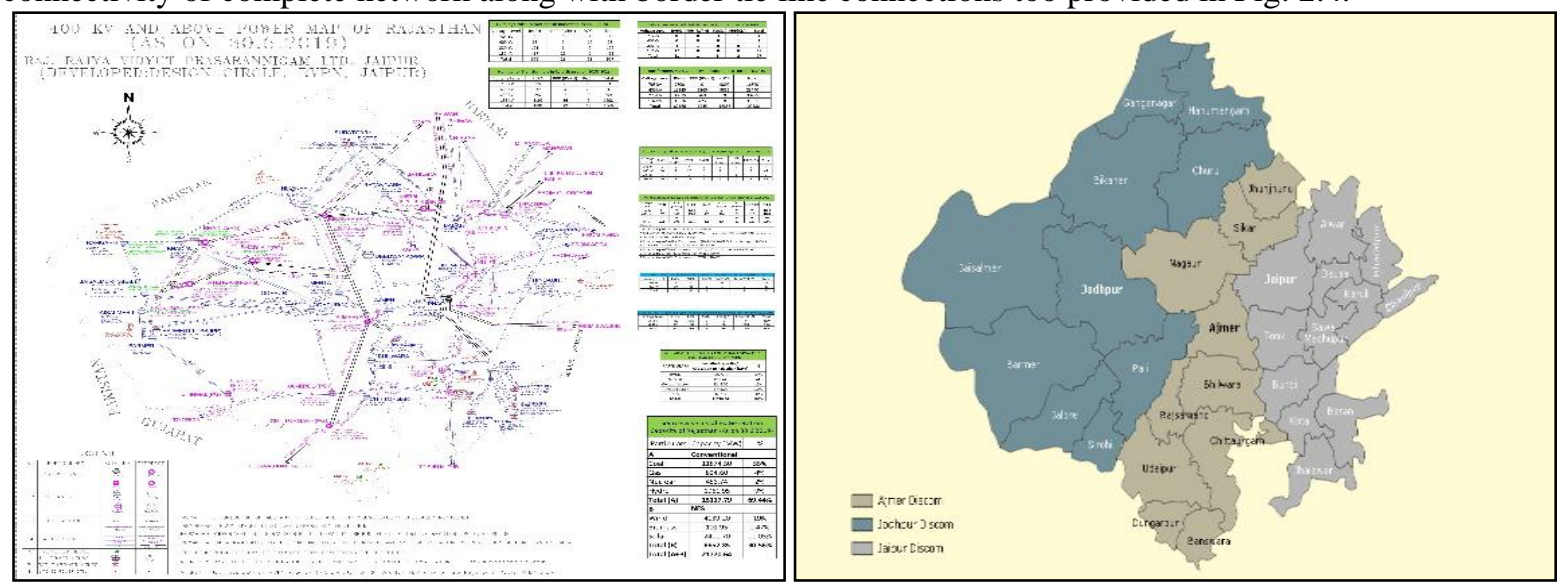

Fig. 2.4 Test Network Power Map \& Distribution Network Division Map

As per fig. 2.4 model using mipower is practiced to prepare based on data recordings and collected an active load of $12874 \mathrm{MW}$ as per the earlier electric power survey report and peak load recordings are concerned. Since area wise the test network is big so it has been divided into three different companies of distribution network as Ajmer, Jodhpur and Jaipur. Up to 10 to 11 districts in each division are divided All the three DISCOMs of Rajasthan were set up as per Companies Act, 1956 by GOR, to completely distribute the roles and responsibilities over the wide area of state. So different zones are pertained to specific calculations are created as shown in Table 2.4.

Table-2.4 Load Based Zones Modeling

\begin{tabular}{|c|c|c|c|c|c|}
\hline \multirow{2}{*}{ Zone No. } & \multirow{2}{*}{$\begin{array}{c}\text { Defined Zones As per Test } \\
\text { Network }\end{array}$} & \multicolumn{2}{|c|}{ Connected load } & \multicolumn{2}{c|}{ Load in 1A } \\
\cline { 3 - 6 } & & Active & Reactive & Active & Reactive \\
\cline { 3 - 6 } & MW & MVAR & MW & MVAR \\
\hline 1 & JAIPUR & 7724 & 2640 & 3658 & 792 \\
\hline 2 & AJMER & 4901 & 2051 & 2321 & 615 \\
\hline 3 & JODHPUR & 5343 & 2319 & 2531 & 696 \\
\hline 4 & NTPC/PGCIL/ISTS & 0 & 0 & 0 & 0 \\
\hline 5 & RVUN & 0 & 0 & 0 & 0 \\
\hline 6 & IPP & 27 & 0 & 13 & 0 \\
\hline 7 & SOLAR_PG & 13038 & 0 & 2608 & 0 \\
\hline 8 & INDUSTRY & 1012 & 190 & 479 & 57 \\
\hline 9 & RAILWAY & 662 & 164 & 313 & 49 \\
\hline 11 & WIND_BANSWARA & 76 & 42 & 36 & 13 \\
\hline 12 & WIND_JSLMR & 63 & 22 & 30 & 6 \\
\hline 13 & WIND_JDP & 282 & 136 & 134 & 41 \\
\hline 14 & WIND_OP & 141 & 64 & 67 & 19 \\
\hline 15 & SOLAR_JSLMR & 52 & 16 & 25 & 5 \\
\hline 16 & SOLAR_JDP & 331 & 154 & 157 & 46 \\
\hline 17 & SOLAR_OP & 536 & 162 & 254 & 49 \\
\hline 18 & SWING_BUS & 0 & 0 & 0 & 0 \\
\hline 19 & REFINERY_LOAD & 250 & 82 & 250 & 82 \\
\hline & Total & $\mathbf{3 4 4 3 8}$ & $\mathbf{8 0 4 2}$ & $\mathbf{1 2 8 7 5}$ & $\mathbf{2 4 7 0}$ \\
\hline
\end{tabular}

The generation holds and operates the thermal, hydel and gas-based power generating stations located. Transmission company looks out operations from 765 to $132 \mathrm{KV}$ lines of system in state and to its connecting's. Dis-coms look out the network lines operating below $132 \mathrm{kV}$ voltage level. All power system equipment's wise modeling is carried out Graphical file as well as database in support to model the network is also created which is than solved using newton Raphson or gauss seidel method. During system creation various zones are created based on network topologies and their contribution to system. Bus Modeling: Initializing with the modeling of bus specific values related to buses organized in test network are created in mipower database as per the table 2.5 briefed hereby.

Table-2.5 Bus Data for Modeling In Software

\begin{tabular}{|l|c|c|c|c|c|c|}
\hline \multirow{2}{*}{ Name of Bus } & \multirow{2}{*}{ Zone } & \multirow{2}{*}{ Area } & \multirow{2}{*}{ Owner } & \multirow{2}{*}{ Voltage (in KV) } & \multicolumn{2}{|c|}{ Voltage Limits (in PU) } \\
\cline { 6 - 7 } & & 5 & 1 & 765 & Min. & Max. \\
\hline AJMER_7 & 4 & 5 & 1 & 400 & 0.9 & 1.1 \\
\hline AJMER_4 & 2 & 3 & 1 & 220 & 0.9 & 1.05 \\
\hline BHIWADI2 & 1 & 2 & 1 & & 0.95 & 1.03 \\
\hline
\end{tabular}

Linking the above tabulated data to the model is carried by inserting from software interface as shown in Fig. 2.5.

DOI Number: https://doi.org/10.30780/specialissue-ICAASET021/007 
ICAASET-2021, 20-21 May, 2020, K.R. Mangalam University, Gurugram

International Journal of Technical Research \& Science (Special Issue) ISSN No.:2454-2024 (online)
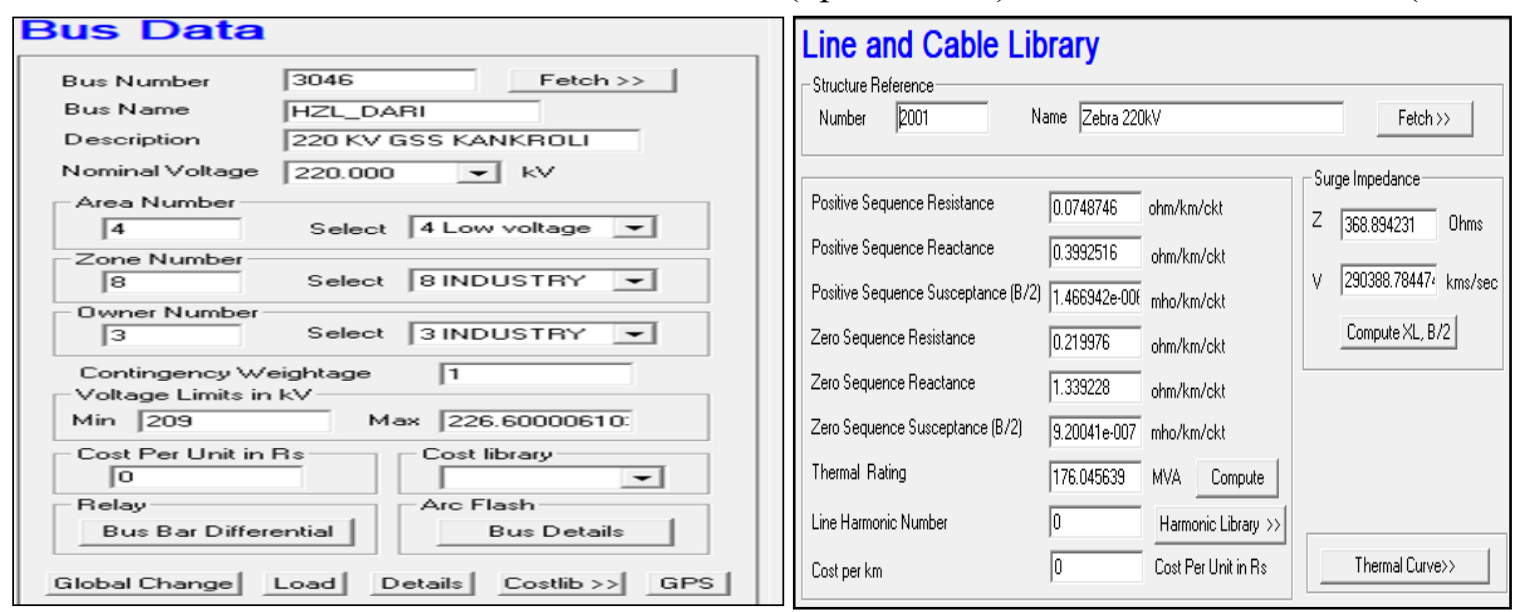

Fig. 2.5 Test Network Bus and line Conductor Modeling Snapshot

Transmission Line \& Conductor Modeling: While modeling a line its sending end, receiving end both have to be signified and the conductor utilized as per the defined voltage level are provided and then model is created. Software snapshot providing details of line and cable library is shown hereby in fig. 2.5. Based on parameters collected such as resistance, reactance and susceptance values, positive and zero sequence values, as inserted into the software model is prepared

Table-2.6Transmission Line Paramters For 765 Kv Network

\begin{tabular}{|c|c|c|c|c|c|}
\hline \multicolumn{2}{|c|}{ Cond. Parameters } & Resistance & Reactance & Susceptance & Thermal Rating \\
\hline \multirow{2}{*}{ Twin HTLS } & + & $1.47 \mathrm{E}-02$ & $2.58 \mathrm{E}-01$ & $2.29 \mathrm{E}-06$ & \multirow{2}{*}{$1.98 \mathrm{E}+03$} \\
\hline & 0 & $4.06 \mathrm{E}-01$ & $1.62 \mathrm{E}+00$ & $1.32 \mathrm{E}+00$ & \\
\hline \multirow{2}{*}{ HTLS P } & + & $1.46 \mathrm{E}-01$ & $3.86 \mathrm{E}-01$ & $1.46 \mathrm{E}-06$ & \multirow{2}{*}{$1.86 \mathrm{E}+02$} \\
\hline & 0 & 4.06E-01 & $1.62 \mathrm{E}+00$ & $1.32 \mathrm{E}+00$ & \\
\hline
\end{tabular}

Generator Modeling: It consist of inserting parameters to model a generator as such database contains library in which various values are fixed.

Table-2.7 Generator Paramters for Database Building In Simulation Application

\begin{tabular}{|c|c|c|c|c|c|c|}
\hline BUS NAME & $\begin{array}{l}\text { RATING- in } \\
\text { MW }\end{array}$ & Q-MIN & Q-MAX & $\begin{array}{l}\text { MVA } \\
\text { Rating }\end{array}$ & $\begin{array}{l}\text { P-RATE- } \\
\text { MIN }\end{array}$ & $\begin{array}{l}\text { P-RATE- } \\
\text { MAX }\end{array}$ \\
\hline STPS220G & 500 & -120 & 250 & 590 & 500 & 500 \\
\hline STPS400G & 500 & -120 & 250 & 590 & 500 & 500 \\
\hline STPS_G & 1320 & -230 & 660 & 1700 & 1320 & 1320 \\
\hline
\end{tabular}

Load Modeling: Load is modeled by inserting values of power factor and active load participation for constant load type load.

\begin{tabular}{|c|l|c|c|c|c|c|}
\hline $\begin{array}{c}\text { S. } \\
\text { No }\end{array}$ & $\begin{array}{c}\text { Load Bus } \\
\text { Name }\end{array}$ & $\begin{array}{c}\text { Active Load in } \\
\text { MW }\end{array}$ & $\begin{array}{c}\text { Power } \\
\text { Factor }\end{array}$ & $\begin{array}{c}\text { Reactive Load in } \\
\text { MVAr }\end{array}$ & $\begin{array}{c}\text { No. Of } \\
\text { SC's }\end{array}$ & $\begin{array}{c}\text { Amount of } \\
\text { Compensation }\end{array}$ \\
\hline 1 & CHIT_7 & 270 & 1 & 3.287 & 0 & 0 \\
\hline 2 & PACHPD2 & 250 & 0.95 & 6.95 & $1 \times 5.43$ & 5.43 \\
\hline 3 & BHIWAD21 & 143.02 & 0.993 & 16.5 & $2 \times 5.43$ & 10.86 \\
\hline
\end{tabular}

Till here all the elements are modeled and created in the document size of 4200 x 3270 inches area size as graphical layout. Now Load flow analysis of network is carried out using fast decoupled load flow method.

As per the problem situation considered in the paper. When high voltages are recorded the possible strategies taken by utilities at their end without being inculcated are outlined hereby.

$>$ The bus reactors will be switched in.

$>$ The manually switchable shunt capacitor banks shall be taken out.

$>$ The switchable line/ tertiary reactors be taken in.

$>$ Synchronous condensers shall be operated for VAR absorption.

$>$ Hydel generators shall be operated as synchronous condenser wherever feasible for VAR absorption, with the consent of SLDC.

$>$ Lightly loaded EHV lines shall be opened keeping in view the security of the balance network with the consent of SLDC for $220 \mathrm{kV}$ in NRLDC through SLDC for $400 \mathrm{kV}$.

$>$ SLDC may resort to regulatory measures by opening of tie lines including those, feeding radial loads in the areas of defaulting Discoms. the same does not adversely affect the evacuation system from existing generation.

During grid disturbances SLDC generates flash report along with report to distribution companies as per the defined levels of issue. May be of Category A: Major, B: Moderate, C: Minor ones are classified. The reaction time of report also various with severity of disturbance. The previous sections till now submits basic information required to understand the complete Rajasthan Network. Based on this ideology network modelling will be presented in the next chapter four but before moving towards modelling part problem identification will be 
ICAASET-2021, 20-21 May, 2020, K.R. Mangalam University, Gurugram

International Journal of Technical Research \& Science (Special Issue) ISSN No.:2454-2024 (online) discussed in the upcoming section. Swing bus is operated as imaginary generator at the location shown in power map. Since majority of network of RSPS system is in synchronism with North Regional Grid division the swing bus point is model by keeping the same ideology.

The state tie line points will also be there near to swing bus. Since in real the test network is having connectivity to national grid at multiple voltage level, such as $765 \mathrm{KV}, 400 \mathrm{KV} 220 \mathrm{KV}$ and $132 \mathrm{kV}$ all are represented in our model. Simulation design of test network is carried on and analytics accomplished using MiPower software is shared hereby: -

$>$ Test network of RSPS is drawn as per power map modeled and simulated up to $132 \mathrm{kV}$ GSS with low renewable integration.

$>$ Real time flow of power system elements as per grid sub stations schedule is studied with identification of the existing parameters and the values applied in power system.

$>$ Real time simulator consists of total 1015 buses including 113 generator buses, 1256 transmission lines, 698 load buses, 180 shunt reactors, 449 shunt capacitors and one static var compensator installed at $400 \mathrm{kV}$ Kankroli GSS.

$>$ Load is represented at $132 \mathrm{kV}$ bus of each $400 \mathrm{kV}$ GSS. Total system load in simulation model is $12,874 \mathrm{MW} \& 2470 \mathrm{MVAR}$ with $0.982 \mathrm{PF}$ as load power factor.

Lastly Table is provided hereby providing losses and exact replica values obtained from multiple load flow studies.

Table-2.9 Load Based Result of Existing RSPS

\begin{tabular}{|l|l|l|l|l|l|l|}
\hline Case Comparison & 1A_20 & 2A_30 & 3A_40 & 4A_50 & 5A_60 & 6A_70 \\
\hline Real Losses in MW & 270.86 & 341.79 & 460.54 & 632.22 & 868.67 & 1207.92 \\
\hline \% Loss & 2.010 & 2.28 & 2.79 & 3.51 & 4.45 & 5.75 \\
\hline
\end{tabular}

Table-2.10 Load Based Result of Existing RSPS

\begin{tabular}{|c|c|c|}
\hline \multicolumn{2}{|l|}{ Parameters } & RSPS LFS \\
\hline \multicolumn{2}{|l|}{ Load MF } & 1.00 \\
\hline \multicolumn{2}{|c|}{ Renewable Energy Integrated \% } & $20 \%$ \\
\hline \multicolumn{2}{|c|}{ Tot. Real Power Load MW } & 12874.69 \\
\hline \multicolumn{2}{|c|}{ Tot. Reactive Power Load MVAr } & 2470.03 \\
\hline \multicolumn{2}{|c|}{ Generation P.F. } & 0.938 \\
\hline \multirow{2}{*}{ Renewable Gen. } & Wind & 1260.25 \\
\hline & Solar & 4197.16 \\
\hline \multicolumn{2}{|c|}{ Tot. Shunt Reactor Injection MVAr (-) } & 25992.26 \\
\hline \multicolumn{2}{|c|}{ Tot. Real Power Loss MW } & 270.86 \\
\hline \multicolumn{2}{|c|}{ Percentage Real Loss } & 2.010 \\
\hline
\end{tabular}

Load Flow results brief outs that with increase of renewable contribution from 20 to $70 \%$ in step of $10 \%$ as results.

\section{CONCLUSION}

The research work submits simulation study of State network electricity system. Existing voltage profile is obtained and problems of violating the voltage profile are identified. Deficiency of test system network in terms of inductive var support is obtained. Since if proper var support is there than it would work as utility function in maintaining voltage profile of network. The base load is having $20 \%$ renewable integration. From the studies following conclusions can be drawn:

$>$ Majority of GSS are submitting peak voltage due to not redressal of inductive system Var .

$>$ Voltage variations must be recorded in terms of voltage variation index basis so that difference in voltage from bus-to-bus voltage could be known exactly.

$>$ Necessary actions to maintain generator var drawls must be carry out.

$>$ Instead of removing Capacitive VAR support during off solar period. Reactors could be penetrated in the same amount to handle the variations due to solar reduction.

As a future scope part apps could be design to maintain var calculations of network for maintaining voltage profile of network as renewable addition and removal may hinder the basic parameters of system.

\section{REFERENCES}

[1] http://powermin.nic.in/sites/default/files/uploads/Indian_Electricity_Grid Code.

[2] P. Kundur, Power System Stability and Control, Tata McGraw Hill publications, New Delhi, 2007.

[3] Nayak, R.N. \& Sehgal, Y.K. \& Sen, Subir. (2006). EHV transmission line capacity enhancement through increase in surge impedance loading level. 4 pp.. 10.1109/POWERI.2006.1632620.

[4] Leandro Ramos de Araujo, Débora Rosana Ribeiro Penido, Sandoval Carneiro, José Luiz Rezende Pereira," Optimal unbalanced capacitor placement in distribution systems for voltage control and energy losses minimization, Electric Power Systems Research, Volume 154, 2018, Pages 110-121, https://doi.org/10.1016/j.epsr.2017.08.012.

[5] B. Vyas, M. P. Sharma and S. Jain, "Feeder Reconfiguration of distribution network using Minimum Power Flow methodology," 2015 Annual IEEE India Conference (INDICON), New Delhi, India, 2015, pp. 1-6, doi: 10.1109/INDICON.2015.7443229. 
ICAASET-2021, 20-21 May, 2020, K.R. Mangalam University, Gurugram

International Journal of Technical Research \& Science (Special Issue) ISSN No.:2454-2024 (online)

[6] Miguel Carrión, Rafael Zárate-Miñano,Operation of renewable-dominated power systems with a significant penetration of plug-in electric vehicles, Energy, Volume 90, Part 1, 2015, Pages 827-835, https://doi.org/10.1016/j.energy.2015.07.111.

[7] N. Sharma, M. P. Sharma, S. Singh and B. Vyas, "Methodology for Valuation of Shunt Capacitor Bank in Power Grid," 2019 10th International Conference on Computing, Communication and Networking Technologies (ICCCNT), Kanpur, India, 2019, pp. 1-7, doi: 10.1109/ICCCNT45670.2019.8944425.

[8] S. Prajapat, M. P. Sharma, S. Johri and B. Vyas, "Loss reduction \& reactive power support in Rajasthan power system: A case study," 2017 Innovations in Power and Advanced Computing Technologies (i-PACT), Vellore, 2017, pp. 1-6, doi: 10.1109/IPACT.2017.8245057.

[9] S. Corsi, "The secondary voltage regulation in Italy," 2000 Power Engineering Society Summer Meeting (Cat. No.00CH37134), Seattle, WA, USA, 2000, pp. 296-304 vol. 1, doi: 10.1109/PESS.2000.867599.

[10] Semich Impram, Secil Varbak Nese, Bülent Oral, Challenges of renewable energy penetration on power system flexibility: A survey, Energy Strategy Reviews, Volume 31, 2020, 100539, ISSN 2211-467X, https://doi.org/10.1016/j.esr.2020.100539.

[11] KROPOSKI, B. Integrating high levels of variable renewable energy into electric power systems. J. Mod. Power Syst. Clean Energy 5, 831-837 (2017). https://doi.org/10.1007/s40565-017-0339-3

[12] S. Corsi, P. Marannino, N. Losignore, G. Moreschini and G. Piccini, "Coordination between the reactive power scheduling function and the hierarchical voltage control of the EHV ENEL system," in IEEE Transactions on Power Systems, vol. 10, no. 2, pp. 686-694, May 1995, doi: 10.1109/59.387904.

[13] Bansilal, \& Dhadbanjan, Thukaram \& Parthasarathy, K.. (1995). An expert system for voltage control in a power system network. 364 - 369 vol.1. 10.1109/EMPD.1995.500754.

[14] P. Rani, M. P. Sharma, B. Vyas and S. Ola, "Loss reduction of Rajasthan power system with Distributed Generation in transmission network," 2016 IEEE 1st International Conference on Power Electronics, Intelligent Control and Energy Systems (ICPEICES), Delhi, 2016, pp. 1-6, doi: 10.1109/ICPEICES.2016.7853597.

[15] Kumar, P., Mathew, L., Shimi, S. L., \& Singh, P. (2016). Need of ICT for Sustainable Development of Power Sector. Proceedings of International Conference on ICT for Sustainable Development, 607-614. doi:10.1007/978-981-10-0129-1_63.

[16] P. Kumar and V. Kumar, "Energy storage options for enhancing the reliability of Power system in the presence of Renewable Energy Sources," 2020 Second International Conference on Inventive Research in Computing Applications (ICIRCA), Coimbatore, India, 2020, pp. 1071-1076, doi: 10.1109/ICIRCA48905.2020.9183349.

[17] R. Panwar, V. Sharma, M. P. Sharma and B. Vyas, "Circulating MVAR control in Rajasthan (India) transmission system," 2016 IEEE 1st International Conference on Power Electronics, Intelligent Control and Energy Systems (ICPEICES), Delhi, India, 2016, pp. 1-6, doi: 10.1109/ICPEICES.2016.7853696.

[18] L. Yan, C. Yongning, T. Haiyan, T. Xinshou, Z. Zhankui and J. Jianqing, "Common Focus and New Requirement on Technical Standards of Renewable Energy Grid Integration," 2019 Chinese Automation Congress (CAC), Hangzhou, China, 2019, pp. 3719-3723, doi: 10.1109/CAC48633.2019.8996943.

[19] Vyas, Bhavesh and Gupta, Mukesh and Sharma, M.P. and Dandotia, Ashish, Sustainable Development of Agriculture Feeders by Solar-Var Incorporation (March 19, 2019). Proceedings of International Conference on Sustainable Computing in Science, Technology and Management (SUSCOM), Amity University Rajasthan, Jaipur - India, February 26-28, 2019, Available at http://dx.doi.org/10.2139/ssrn.3355181.

[20] D. Mitra, M. P. Sharma, T. Suman and B. Vyas, "Identification \& Reduction Of Circulating Mvar Loops At High Voltage Substations," 2020 21st National Power Systems Conference (NPSC), Gandhinagar, India, 2020, pp. 1-6, doi: 10.1109/NPSC49263.2020.9331763. 